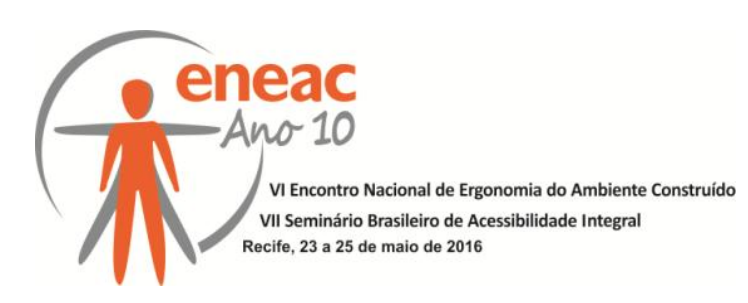

\title{
INTERVENÇÃO ERGONÔMICA EM POSTO DE ATENDIMENTO AO PÚBLICO: UM CASO DE INSERÇÃO DA ERGONOMIA EM PROJETOS ARQUITETÔNICOS
}

\author{
COSTA, Ana Paula Lima (1) \\ VILLAROUCO, Vilma (2) \\ (1) UFPE, Mestre em Design \\ e-mail:aplimacosta@gmail.com \\ (2) UFPE, Doutora Eng. Produção, UFPE, \\ e-mail:villarouco@hotmail.com
}

\begin{abstract}
RESUMO
Este artigo relata a inclusão de preceitos ergonomicos no processo de elaboração de um projeto arquitetônico de reforma de um posto de atendimento ao público de uma repartição pública. O projeto arquitetônico seguiu as etapas de execução descritas pela NBR 13532. A MEAC foi utilizada para compreender a relação dos usuários com o ambiente construído. Os resultados da avaliação ergonômica forneceu elementos que conduziu a adequação do espaço físico. A obra de reforma foi realizada apesar de limitações operacionais da repartição pública. Concluiu-se que a ergonomia contribuiu com a prática de arquitetura ao ser inserida nos procedimentos de planejamento.
\end{abstract}

Palavras chave: Repartição pública; processo de projeto; metodologia ergonômica.

\begin{abstract}
This article reports the inclusion of ergonomic principles in the process of an architectural renovation project of a service station to the public in a public office. The architectural design followed the implementing steps outlined by NBR 13532. The MEAC was used to understand the relationship of users with the built environment. The ergonomic evaluation results provided evidence that led the suitability of physical space. The work of reform was carried out despite operational limitations of the government agency. It was concluded that the ergonomics contributed to the practice of architecture to be included in the planning procedures.
\end{abstract}

Keywords: Public repartition; design process; ergonomic approach

\section{INTRODUÇÃO}

Ergonomia e arquitetura estão ligadas pelo planejamento e pelo questionamento das atividades. Através da ergonomia, é possível entender as atividades humanas e seus requisitos de projeto; através da arquitetura, é possível fornecer os elementos para fazer as atividades acontecerem (PATTERSON, 2009). A arquitetura voltada para o usuário atende aos anseios ambientais buscando adequar o espaço à função (VILLAROUCO, 2011). A ergonomia aplicada à concepção propõe a utilização de métodos e instrumentos para avaliação e desenvolvimento objetivo de novo conceito de planejamento (GIUSEPPE, 2009). 


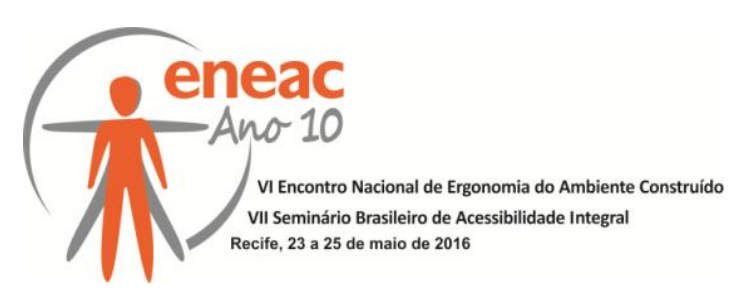

O caminho que vai da concepção inicial à definição plena é considerado pelo IAB (2013) como o processo projetual, sendo uma série de sucessivos procedimentos relativamente autônomos, organizados em fases - estudos iniciais, anteprojeto, projeto - que fazem parte de um todo, articulado através da intenção que permeia todo o processo. Toda a coleta de dados, sua análise e a avaliação dos problemas e resultados são procedimentos básicos na prática do projeto.

A metodologia de projeto arquitetônico procura racionalizar as atividades criativas e apoiar o projetista para a solução de problemas cada vez mais complexos, uma vez que a tomada de decisão significa escolher um curso de ação entre muitas possibilidades (KOWALTOWSKI et al, 2006). Todos os elementos que compõem o ambiente arquitetônico são elaborados de acordo com uma lógica de utilização, que serão ajustados a partir das atividades que pretendem abrigar. Por isso, ao projetar é necessário realizar uma análise minuciosa das atividades previstas, necessidades e anseios dos indivíduos que utilizarão o lugar. Utilizando a análise ergonômica do ambiente para se verificar, in loco, as relações entre os elementos de arquitetura e o desempenho das atividades que eles querem apoiar, se conhece esses fatores como recursos para o projeto proporcionar uma relação saudável entre as pessoas e o ambiente (ALMEIDA, 2009).

Tendo em vista que, para propor uma ocupação física de um ambiente devem-se identificar as atitudes comportamentais e suas influências dentro do ambiente, faz-se necessário levar em consideração as necessidades daqueles que irão utilizar o ambiente. Assim a ergonomia, disciplina científica que atua de forma sistemática utilizando-se de instrumentos provenientes da ciência e da tecnologia, e que tem como foco o homem em situação real de trabalho, torna-se uma importante ferramenta de auxílio para a compreensão do ambiente construído e sua influência sobre o usuário.

\section{METODOLOGIA APLICADA NO PROJETO DE REFORMA}

A demanda de um projeto arquitetônico de reforma de um posto de atendimento ao público de uma repartição pública vislumbrou a possibilidade de inserção dos preceitos ergonômicos de adaptabilidade do ambiente às funções e necessidades dos indivíduos no tradicional método de planejamento arquitetônico. Desta forma, o ponto de partida para a concepção do projeto deveria ser a compreensão das funções de trabalho e dos indivíduos que trabalhariam no espaço. Os resultados desta pesquisa baseariam as recomendações que ajudariam a criar ambientes de trabalho que permitiriam os funcionários trabalhar com conforto.

Tendo em vista que um espaço de trabalho ergonomicamente adequado visa ajustar a situação de projeto ao homem, o projeto realizado deveria ter como elemento primordial o usuário do ambiente, em seus aspectos físicos, culturais, psicossociais e cognitivos. Desta forma, a avaliação ergonômica do ambiente consistirá em pesquisar referências para o projeto, no qual a investigação de atividade de trabalho não se limitará a descrever a ação humana, mas visará proporcionar conhecimento útil para ser utilizado em concepções de planejamento.

Entendendo que, ao se analisar ambientes de trabalho devem-se utilizar abordagens complementares para atender às necessidades físicas e psíquicas dos usuários, foi adotada a abordagem sistêmica da Metodologia Ergonômica de Avaliação do Espaço Construído MEAC (VILLAROUCO, 2009), que analisa o espaço físico conjugando avaliações físicas e espaciais às ferramentas de identificação da percepção ambiental dos usuários.

A partir do diagnóstico e das preposições ergonômicas, foi elaborado o projeto de reforma do ambiente visando à implantação das alterações necessárias para adequação do ambiente às condições adequadas de uso. 


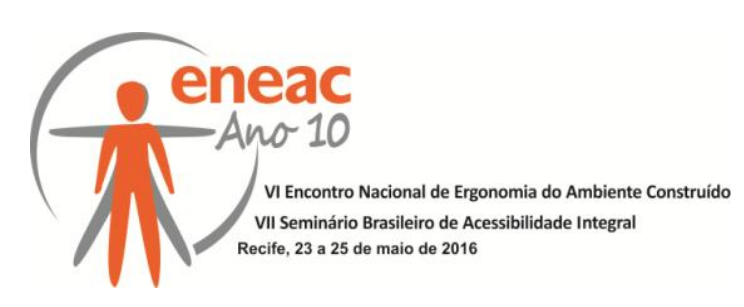

\subsection{Aplicação da análise ergonômica}

A MEAC (VILLAROUCO, 2009) é pautada em uma abordagem sistêmica, e abrange variáveis das áreas envolvidas no espaço edificado, tendo como elemento primordial o usuário deste espaço e suas percepções ambientais, por ser o elemento que absorve os impactos que o ambiente transmite. A metodologia é aplicada em quatro etapas analíticas: Análise Global do Ambiente, Identificação da Configuração Ambiental, Avaliação do Ambiente em Uso no Desempenho das Atividades e Percepção Ambiental. Concluídas as análises, elabora-se o Diagnóstico Ergonômico do Ambiente e as Proposições.

\subsubsection{Análise Global do Ambiente}

$\mathrm{Na}$ fase de análise global do ambiente são colhidas informações sobre o ambiente e as atividades, sendo formuladas as primeiras hipóteses a respeito das intervenções do espaço na execução das atividades do trabalho.

\subsubsection{Descrição da Unidade Produtiva}

O espaço físico faz parte de uma empresa pública responsável pela administração dos tributos de competência da União. Instalada em uma galeria comercial, ocupa uma área de $164,00 \mathrm{~m}^{2}$. O setor que sofreu a intervenção tem como competência executar as atividades de atendimento ao público, tais como prestar informações, formalizar processos administrativos e executar os procedimentos de recepção e retificação de documentos.

No ambiente estão lotados quinze trabalhadores, com jornada de seis horas. Os funcionários são distribuídos em dois turnos de trabalho, um pela manhã e outro pela tarde, e os postos de trabalho são compartilhados entre os ocupantes dos diferentes turnos.

\subsubsection{Percepção do Observador}

O local é limpo e esta em bom estado de conservação. Não foram percebidos ruídos excessivos, nem iluminação deficiente, mas a temperatura do ambiente se mostrou irregular, com alguns locais mais quentes do que outros. Percebe-se uma carência de sinalização para orientar o público que comparece ao local. A tubulação descendo do teto dá um aspecto de improvisação na solução do cabeamento elétrico e lógico (Figura 01).

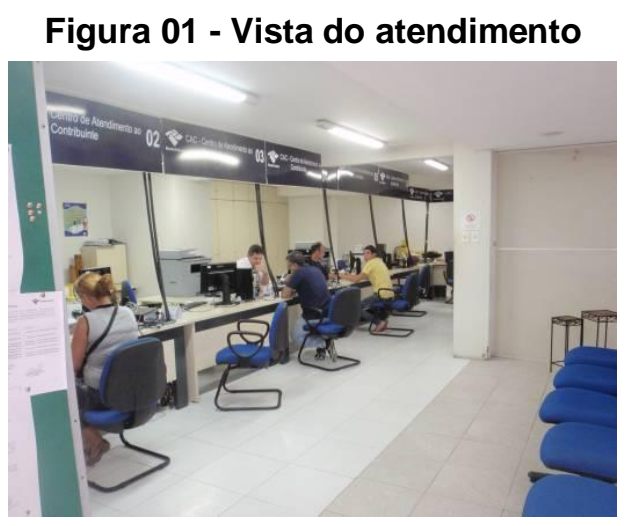

Fonte: Autoras 


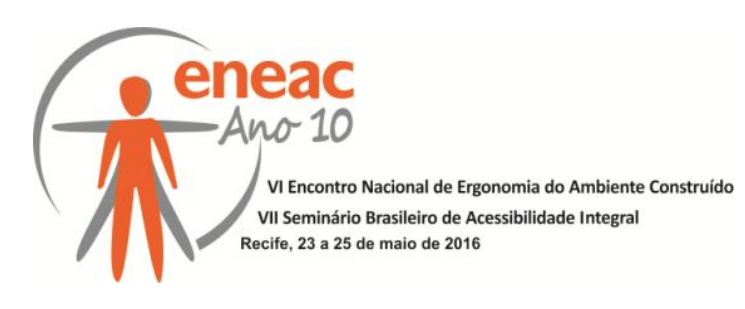

\subsubsection{Identificação da Configuração Ambiental}

Nesta fase da análise do ambiente identificam-se os condicionantes físico-ambientais, através do levantamento dos dados do ambiente.

\subsubsection{Leiaute}

O local está dividido em dois setores: área de espera do público e área de atendimento. $\mathrm{Na}$ sala de espera se obtém informações gerais sobre os serviços prestados e se recebe uma ficha para se encaminhar ao atendimento, que é previamente agendado pela internet. Um painel eletrônico informa a chamada para o atendimento. $O$ serviço de protocolo tem área de espera específica, próxima aos atendentes, e não utiliza o sistema de agendamento eletrônico.

Não há portas isolando a sala de espera, a sala de atendimento e a área de acesso exclusivo de funcionários. O ambiente de atendimento é dividido entre quatro tipos de serviços, que atendem a assuntos específicos: protocolo, atendimento, plantão fiscal e chefia. Há um local reservado para uma copa visível pelo público, o que causa inibição aos funcionários ao fazer pequenas pausas, por dar a impressão de não estarem trabalhando com afinco e gerarem comentários depreciativos por parte dos visitantes. A figura 02 mostra a planta baixa do ambiente.

Figura 02 - Planta baixa de leiaute

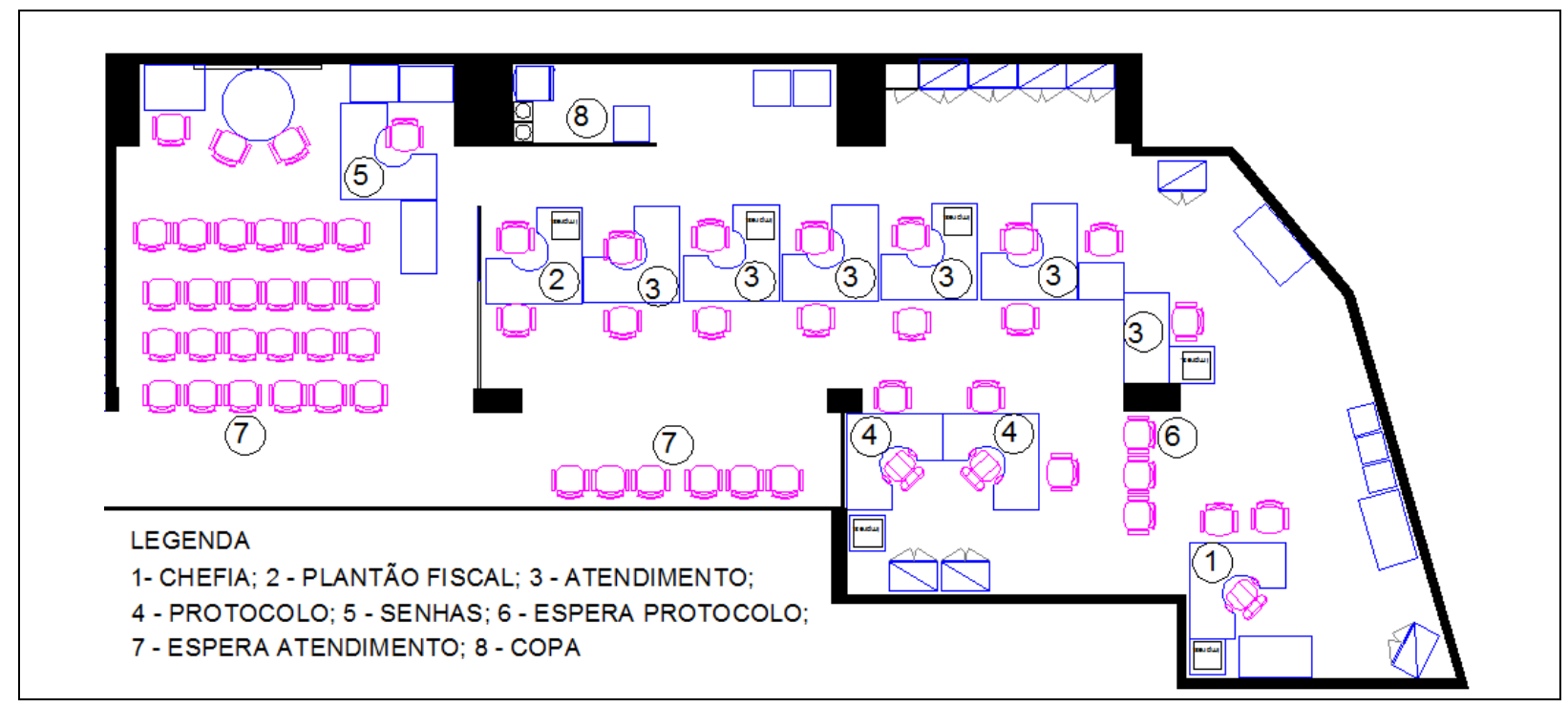

Fonte: Autoras

\subsubsection{Fluxos de Circulação}

Só há uma porta de entrada e saída. Existem dois tipos de fluxos de circulação: o fluxo interno dos trabalhadores e o fluxo dos visitantes. Os trabalhadores acessam os seus postos de trabalho por um corredor delimitado pela mesa de entrega de senhas de atendimento, e depois por uma circulação interna até as mesas de atendimento e a mesa da chefia. Os contribuintes ao chegarem ao ambiente passam pelo espaço de espera e se dirigirem à mesa de entrega de fichas, retornam ao local de espera e aguardam o chamado para ser dirigirem ao local de atendimento (Figura 04). 


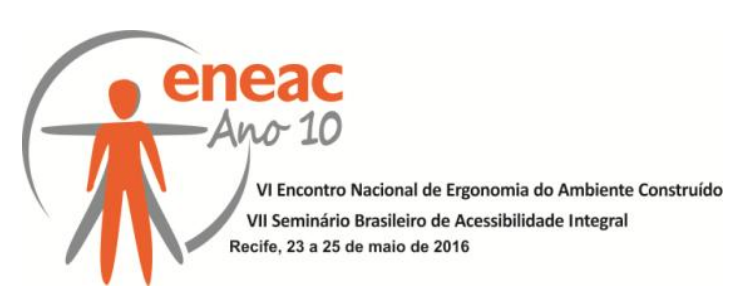

Os trabalhadores permanecem sentados a maior parte da sua jornada, apenas se dirigindo às mesas vizinhas para discutir algum caso ou tirar alguma dúvida. $O$ fluxo interno é baixo, mas existe uma interação muito grande com a chefia, que constantemente se dirige aos postos de trabalho para trocar informações com os trabalhadores (Figura 03).

Figura 03 - Planta baixa de fluxos de circulação

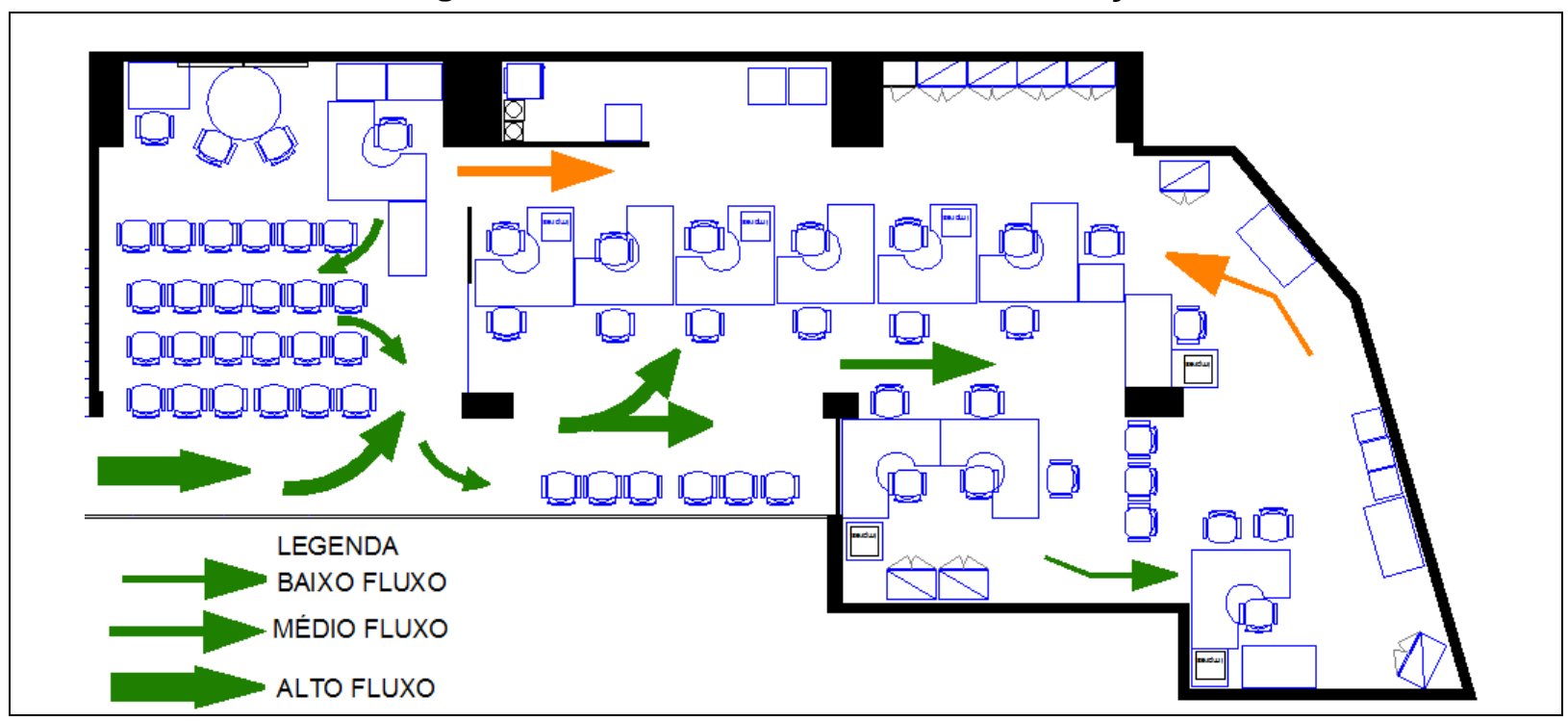

Fonte: Autoras

Apesar de ser um ambiente aberto, o deslocamento interno não é claro, por não haver sinalização indicativa nem informativa dos procedimentos de atendimento, tais como "não entrar no local de atendimento sem ser autorizado" (Figura 04). Desta forma, o fluxo de contribuintes não obedece ao ritmo prescrito, pois é comum eles entrarem na sala de atendimento sem autorização, pois não há portas limitando o acesso às áreas restritas ou áreas de atendimento.

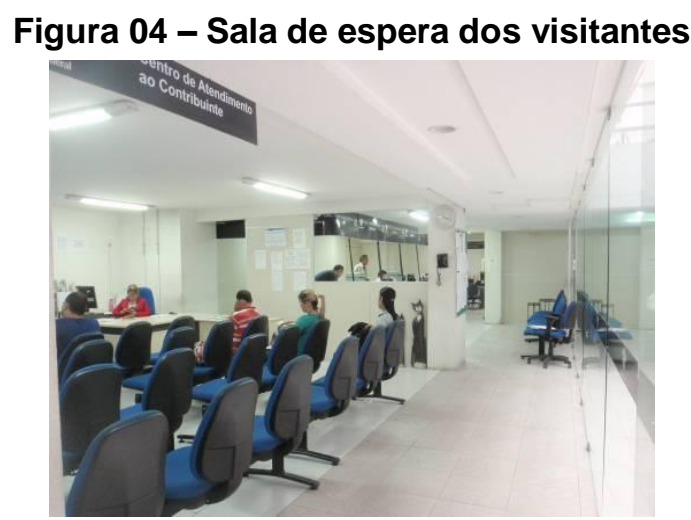

Fonte: Autoras

\subsubsection{Postos de Trabalho}

As salas são equipadas com estações de trabalho no formato "L" com gaveteiro fixo, cadeiras giratórias sem regulagem de profundidade do assento e do encosto para os 


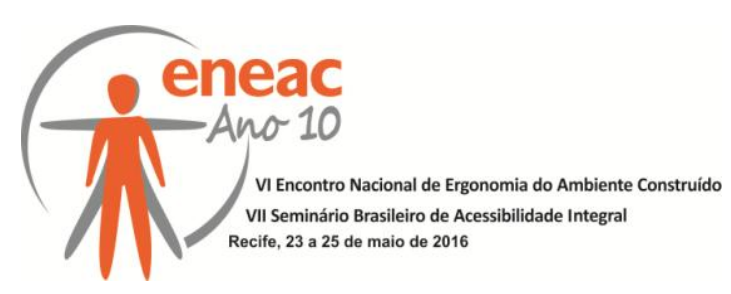

atendentes, e cadeiras sem regulagens para os contribuintes. Os postos de trabalho dos atendentes são agrupados sem painéis divisórios entre eles.

Os equipamentos utilizados pelos atendentes são: dois monitores de computador, teclado, CPU, e impressora compartilhada a cada duas mesas. A mesa que recebe a impressora fica com pouco espaço, devido ao grande volume do equipamento. A fiação dos equipamentos se distribui por uma calha fixada em uma viga, localizada acima das mesas de trabalho, e desce para as mesas através de uma tubulação flexível, próxima às pessoas que estão sendo atendidas. Apesar de ter conexão com a mesa, a fiação fica exposta ao se conectar com os equipamentos, oferecendo um risco de acidentes e dando um aspecto desordenado ao ambiente (Figura 05). As mesas se posicionam continuamente, sem septos individualizando os espaços de trabalho, o que prejudica o atendimento, pela interferência sonora e pela perda de privacidade, tendo em vista que as informações prestadas são de caráter privativo dos contribuintes.

\section{Figura 05 - Vista da fiação com a tubulação exposta descendo do teto para os postos de trabalho}

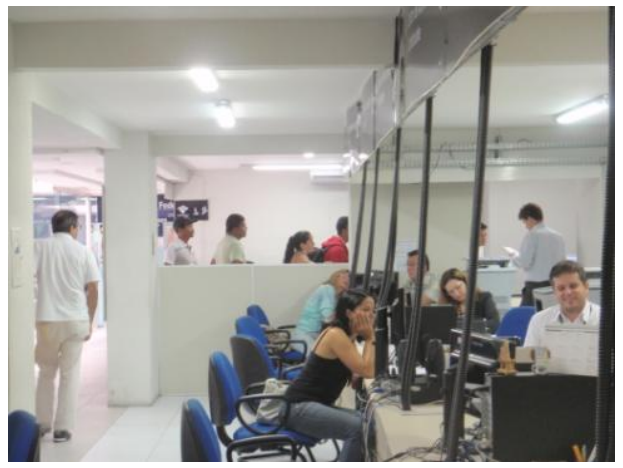

Fonte: Autoras

\subsubsection{Medições das condições físicas do ambiente}

As avaliações de conforto ambiental foram realizadas conforme os parâmetros estabelecidos na NR-17 (BRASIL, 1978), sendo observado o atendimento das recomendações das condições de conforto quanto aos níveis de ruído, índice de temperatura e iluminação adequada.

O método de verificação de iluminação de interiores foi o determinado pela NBR 5382 ABNT (1991) e os resultados foram comparados com os níveis estabelecidos pela norma NBR 5413 (1991). A iluminância encontrada estava abaixo do valor recomendado pela NBR5382 de 500 lux.

O índice do conforto acústico foi verificado de acordo com a NBR 10152, que define os níveis de ruído para conforto acústico para áreas de trabalho. $O$ índice de ruído efetivo encontrado variou entre $51,5 \mathrm{~dB}(\mathrm{~A})$ a $73,6 \mathrm{~dB}(\mathrm{~A})$. As fontes de ruídos detectadas foram a conversação dos usuários durante os atendimentos, e o painel eletrônico na sala de espera, que emite um sinal $(72,9 \mathrm{~dB}(\mathrm{~A}))$ para destacar um novo chamado. Desta forma, observa-se que o ambiente apresenta níveis de ruídos acima do nível de conforto determinado pela NBR 10152.

O índice do conforto térmico foi verificado de acordo com a NR 17, que estabelece o índice de temperatura efetiva entre $20^{\circ} \mathrm{C}$ e $23^{\circ} \mathrm{C}$. A temperatura do ambiente na sala de atendimento no dia considerado quente variou entre $24.9^{\circ}$ e $25.6^{\circ}$, e no dia considerado frio variou entre $22.8^{\circ}$ e $23.6^{\circ}$. Na sala de espera a temperatura do ambiente no dia considerado quente variou entre $25.6^{\circ} \mathrm{C}$ e $26.2^{\circ} \mathrm{C}$; e no dia considerado frio variou entre $23.6^{\circ}$ e $24^{\circ} \mathrm{C}$. 


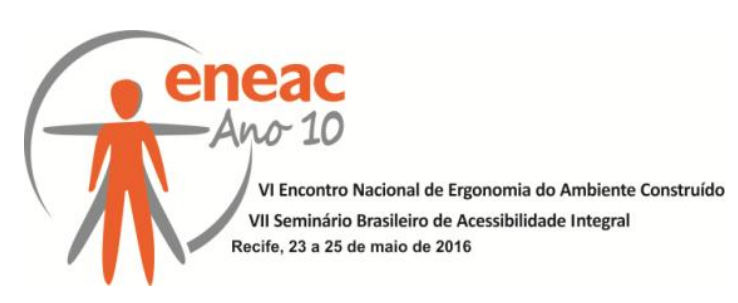

Desta forma, observa-se que as temperaturas encontradas encontram-se acima do índice estabelecido pela norma NR-17.

\subsubsection{Avaliação do Ambiente em Uso no Desempenho das Atividades}

A etapa da avaliação do ambiente em uso no desempenho das atividades visa identificar o quanto facilitador ou inibidor o ambiente representa ao desenvolvimento das atividades. Para realizar esta análise foram realizadas entrevistas com os usuários do ambiente para conhecer os procedimentos e trabalho e, através da observação direta, foi verificado o desenrolar das atividades no decorrer de uma jornada de trabalho.

Tendo em vista que a função do ambiente de trabalho é atender ao público, ao observar o ambiente sendo utilizados pelos seus usuários, verificou-se que a falta de sinalização do funcionamento no local aliado com o tipo de arranjo físico é um fator que prejudica o andamento dos serviços. A localização da recepcionista que entrega as fichas de atendimento é recuada em relação do acesso externo e interno do prédio, o que facilita a entrada de pessoas no atendimento sem terem recebidos a devida ficha de chamada. Quando se forma fila de contribuintes para pegar a ficha de chamada, o acesso ao local de espera é dificultado. Quando as cadeiras da sala de espera estão ocupadas o acesso ao posto de autoatendimento fica impedido, pela falta de espaço de circulação.

A forma de distribuição dos serviços dentro do ambiente de atendimento também não é adequada, pois existe uma espera específica para as pessoas que vão ao protocolo, que não requer ficha para ter 0 atendimento. Mas, pela falta de sinalização, é comum encontrar pessoas dentro da área de atendimento sem saber que rumo tomar. $O$ fato dos atendentes realizarem diferentes tipos de atendimento, dependendo do assunto a ser tratado, algumas vezes causa aborrecimentos, por acontecer de um setor estar sem atendimentos agendados enquanto que outro setor possa estar com indivíduos esperando para serem atendidos.

Existe uma área reservada para copa, mas o seu posicionamento visível e próximo ao local de atendimento causa constrangimentos quando o trabalhador utiliza-a no momento que visitantes esperam para ser atendidas.

\subsubsection{1. $\quad$ Análise da Percepção do Usuário}

A análise da percepção é dividida em duas etapas, que abordam as características espontâneas que os usuários registram sobre o ambiente que utilizam. Através de entrevistas procurou-se colher as impressões dos usuários, comparando com as imagens simbólicas sobre o ambiente físico com as percepções sobre o ambiente real que eles ocupam. A pesquisa foi respondida por 10 trabalhadores do ambiente, representando um percentual de $66,6 \%$ de participação na pesquisa.

\section{- $\quad$ Características Espontâneas - 1ª etapa}

Para este processo de avaliação foi utilizada a pergunta "Quando você pensa em um ambiente de atendimento ao público o que lhe vem à mente?". A pergunta visa obter respostas espontâneas sobre 0 ambiente. As respostas abertas foram agrupadas pela semelhança, e apontaram que o ambiente de trabalho ideal seria, primeiramente, aquele que fosse confortável, tanto para os trabalhadores como para o público, tranquilo, espaçoso e bem dividido. As características de ambiente organizado, bem decorado e de fácil acesso, e mobiliado com guiches separados e mesas ergonomicas foram citadas com menor frequencia. As caracteristicas dos condicionantes físicos citados foram as temperatura e 


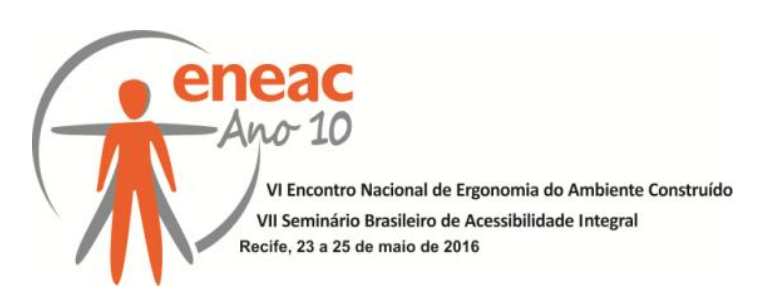

iluminação adequadas. As características que foram citadas individualmente foram a presença de bons equipamentos, ambiente limpo e local para guardar pertences pessoais.

\section{- $\quad$ Características Induzidas - 2ª etapa}

Nesta etapa, a pergunta "Quando você pensa no local de atendimento aompúblico aonde voce trabalha o que lhe vem à mente?" foi realizada com a finalidade de distinguir o que é objetivo do que é subjetivo na percepção do usuário. Os servidores ressaltaram, primeiramente, que o espaço é mal distribuído, revelando o descontentamento com o arranjo físico do ambiente. As características que também afetavam negativamente com mais frequência os usuários foram com a refrigeração irregular, a inadequação do ambiente e o barulho ambiental. As faltas de privacidade e de controle de entrada citadas pelos usuários refletem a insegurança sentida no local.

\section{- $\quad$ Análise da Percepção sobre o Ambiente}

A partir das observações feitas pelos usuários do ambiente, observa-se que os usuários almejam um ambiente confortável e agradável, o que pode ser traduzido em um ambiente espaçoso, com uma boa distribuição interna, mobiliário adequado ao atendimento ao público e com boas condições térmicas e de luminosidade. A partir das observações dos usuários, o ambiente por eles ocupado pode ser considerado inadequado, pela refrigeração irregular, pelo ruído percebido no local, pela deficiente disposição do espaço, pela falta de controle de entrada e falta de privacidade.

Portanto, a partir das percepções dos usuários do ambiente, verifica-se que o ambiente não está adequado às realizações das atividades de atendimento ao público, sendo necessárias diversas intervenções para adequá-lo ao tipo de serviço realizado no local.

\subsubsection{Diagnóstico ergonômico e proposições}

O diagnóstico ergonômico apresenta as características do ambiente que estão em desacordo com o propósito de utilização do local. As proposições ergonômicas são as recomendações para solução das questões que interferem negativamente na utilização do ambiente.

Em relação ao leiaute, verificou-se que a área de entrega de fichas estava fora da rota de entrada; que o serviço de protocolo deveria se localizar sem em área que não conflitasse com os demais atendimentos; e que deveria haver uma distinção entre os diversos tipos de atendimentos.

Quanto ao fluxo de circulação, deveriam ser colocadas portas de entrada para controlar o acesso dos visitantes ao local de atendimento; a sinalização interna deveria prestar orientações básicas de formas de procedimento e atendimento ao local.

Os resultados da pesquisa apontaram que, apesar de se tratar de uma edificação com boas condições de conservação e instalações em bom estado de funcionamento, alguns aspectos do ambiente estão em desacordo com a sua finalidade, acarretam desconfortos aos usuários e prejudicando o desempenho das suas atribuições. O ambiente físico tem como deficiência a iluminação das salas de trabalhos, em índices abaixo da norma reguladora, podendo a vir causar danos nos usuários. 


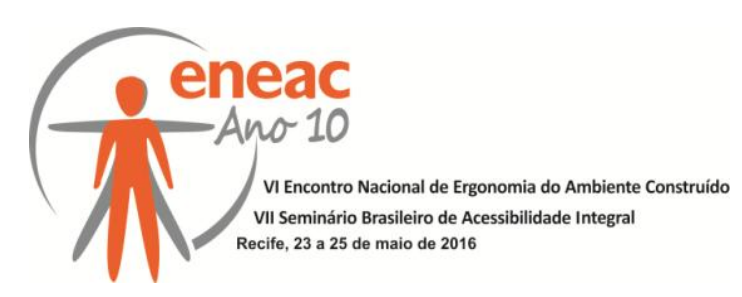

\section{PROJETO DE REFORMA DO AMBIENTE FÍSICO}

O projeto arquitetônico de reforma do ambiente seguiu as etapas de execução da atividade técnica do projeto descritas pela NBR 13532 (ABNT, 1995): levantamento de dados, programa de necessidades, estudo de viabilidade, estudo preliminar, anteprojeto e projeto para execução. Estas etapas podem ser entendidas como a descrição do processo de projetar, tendo uma estrutura linear que se assemelha a um mapa de tomada de decisões, compondo um método de projetação por se caracterizar como procedimentos adotados pelos profissionais arquitetos.

A partir do reconhecimento das fases, tornou-se possível inserir a abordagem ergonômica compatibilizando com as tomadas de decisões. A primeira fase consistiu no levantamento de dados e programa de necessidades com as informações que precedem o projeto arquitetônico. A segunda fase foi a do esboço e consistiu em testar as hipóteses levantadas que foram usadas no projeto arquitetônico. A terceira fase de definição compreendeu na tomada de decisões de projeto, sendo elaborado o projeto executivo da obra.

A análise ergonômica do ambiente contribuiu em diversos aspectos no processo de projeto:

- Na fase de levantamento de dados, na qual se obtém informações técnicas sobre as características físicas e legais do espaço no qual será realizado o projeto, foram utilizadas as informações obtidas na Análise Global do Ambiente, na Identificação da Configuração Ambiental e na Avaliação do Ambiente em Uso no Desempenho das Atividades.

- O Programa de necessidades de arquitetura se utiliza das referências do levantamento de dados e produz as informações necessárias à concepção arquitetônica do ambiente as características funcionais ou das atividades em cada ambiente. Nesta etapa, além das demandas administrativas e funcionais, foram considerados os dados obtidos na Percepção Ambiental dos usuários.

- As segundas e terceiras fases de definição de projeto arquitetônico (esboço e projeto executivo) foram referenciadas no Diagnóstico Ergonômico do Ambiente e nas Proposições Ergonômicas.

Além das demandas do espaço físico, houve imposições funcionais ao projeto, devido ao fato que o ambiente objeto de estudo estava em pleno funcionamento e não poderia interromper suas atividades de prestação de serviço à população. Desta forma, as intervenções deveriam interferir o mínimo possível na rotina da repartição pública, sem interdição do local, devendo ocorrer durante o período noturno e nos finais de semanas. Também foram impostas restrições orçamentárias, devendo haver o reaproveitamento dos equipamentos e mobiliários existentes, e preservação das instalações prediais de sistema de refrigeração, de rede elétrica e de lógica, sendo passível de adequações.

Seguindo os pressupostos acima, o projeto apresentado procurou atender os seguintes requisitos:

- Isolar com uma barreira física o atendimento da sala de espera, e instalar portas para controlar o acesso do contribuinte ao atendimento. Este isolamento também melhorará o conforto acústico, pelo isolamento do ruído da sala de espera.

- Alterar a distribuição interna de modo a proporcionar um melhor desempenho das atividades. Deslocamento do posto de entrega de fichas de atendimento para controle de entrada dos visitantes. Localização do serviço de protocolo nas primeiras mesas, de modo a não sobrecarregar o fluxo dos outros tipos de atendimento com hora marcada. Localização do serviço de plantão fiscal em local distinto dos outros atendimentos. Transferir a copa para local que não seja visível aos visitantes.

- Adquirir estações de trabalhos com septos entre as mesas, de modo a isolar 


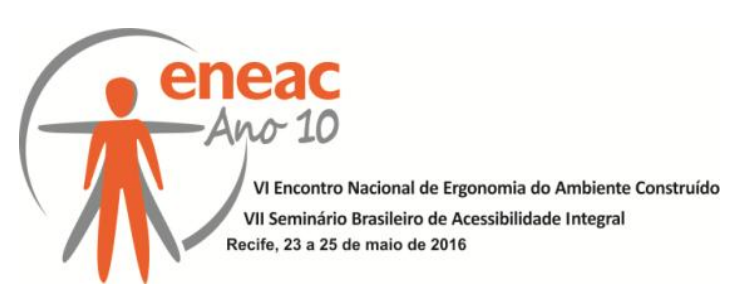

acusticamente cada atendimento e fazer distinção entre os espaços individuais de cada usuário, promovendo resguardo aos visitantes para tratar seus assuntos com segurança e privacidade.

- Remoção e colocação em tubulação das fiações elétricas e lógicas, de modo a promover a segurança das instalações e dos usuários, e melhorar o aspecto visual do ambiente.

- Complementação e relocação das luminárias para proporcionar iluminação adequada no posto de trabalho.

- Reestruturação do sistema de refrigeração, de modo a condicionar o clima de maneira mais uniforme, com a complementação e relocação das máquinas.

As intervenções dos ambientes com o novo leiaute proposto estão representadas na Planta baixa de proposta (Figura 05).

Figura 05 - Planta baixa de leiaute proposto

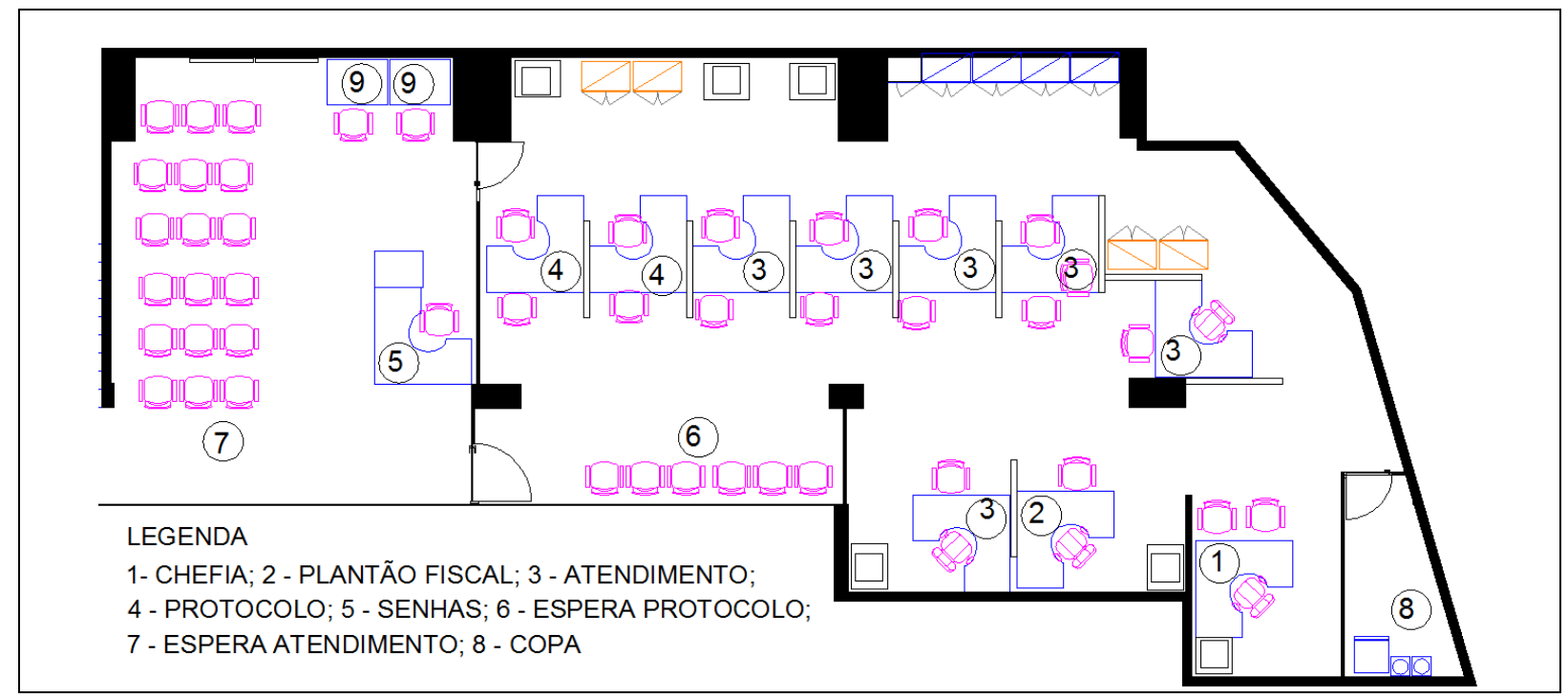

Fonte: Autora

\section{OBRA DE REFORMA DO AMBIENTE FÍSICO}

A execução da obra de reforma do ambiente foi realizada seguindo as limitações orçamentárias e disponibilidade de tempo da repartição pública, que impuseram restrições de custo e de prazo de execução, mas que não impediram a implantação do projeto. As limitações de realizar as obras conduziram a realização de uma obra com aproveitamento de mobiliários e equipamento existentes. Também não seria possível interromper o atendimento ao publico, desta forma, as obras decorreram nos períodos noturnos e durante fins de semana.

Apesar das restrições impostas, foram realizadas as seguintes intervenções:

- Isolamento com um painel de vidro transparente a sala de espera dos visitantes da sala de atendimento ao público.

- Mudança do leiaute dos postos de atendimento, deslocando o posto de recepção para ficar junto à porta de entrada. As primeiras estações de trabalho foram 


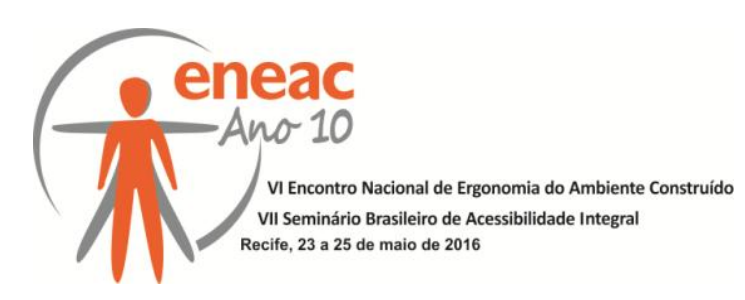

destinadas ao serviço de protocolo, seguido dos outros tipos de atendimento, sendo por ultimo o posto de atendimento de plantão fiscal. A copa foi deslocada e isolada com divisórias, não sendo mais visível aos visitantes.

- Instalação de septos verticais entre as mesas, isolando acusticamente e visualmente os atendimentos.

- Remoção das fiações elétricas e lógicas, que passaram a ser embutidas e canalizadas por baixo das mesas de trabalho. Adequação das luminárias para proporcionar iluminação adequada ao posto de trabalho e complementação e relocação das máquinas de refrigeração.

A figura 06 mostra o ambiente depois das intervenções.

\section{Figura 06 - Vista dos postos de atendimento com os septos verticais}

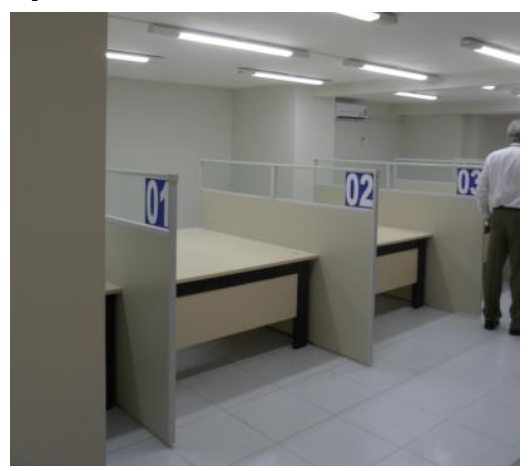

Fonte: Autoras

\section{CONCLUSÃO}

A partir da solicitação de um projeto de reforma para realizar intervenções no ambiente físico de um local de atendimento ao público uma repartição pública, foi realizada uma análise ergonômica para conhecer as necessidades do ambiente e dos usuários. O diagnóstico ergonômico gerou as preposições que balizaram o projeto de intervenção no ambiente físico.

As limitações orçamentárias e operacionais não impedindo que as obras fossem realizadas nem interferiram na qualidade das soluções, que se traduziram em mudanças de distribuição do espaço e adequações das instalações prediais. O que poderia ser um empecilho à concretização dos propósitos da intervenção se mostrou um aliado na demonstração que as proposições ergonômicas podem ser obtidas a partir de intervenções pontuais, e assim, adequar o ambiente aos usuários.

Desta forma, verificou-se que a utilização da análise ergonômica do ambiente construído para conhecer as condições do ambiente e as necessidades dos usuários se mostrou positiva por fazer a interação entre duas áreas de conhecimento e atuação: a arquitetura, na concepção de ambientes construídos, e a ergonomia, na compreensão das interações entre o ser humano e o ambiente que o envolve e suporta suas atividades.

Concluiu-se, então, que a ergonomia pode contribuir com projetos de ambientes construídos sendo inserida nos procedimentos de planejamento. 


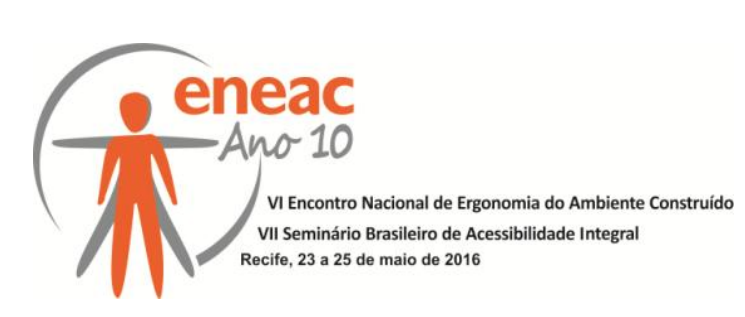

\section{REFERÊNCIAS}

ALMEIDA, Maristela Moraes de. Architectural conception and Evaluation of the Environment: Relations between human factors, and environmental factors. In: Anais do 17th World Congress on Ergonomics-IEA 2009, Beijing, China. 2009

ASSOCIAÇÃO BRASILEIRA DE NORMAS TÉCNICAS. NBR 10152: Nível de ruído para conforto acústico. Brasil, 2000

NBR 13532- Elaboração de projetos de edificações Arquitetura. 1995

NBR 5382 - Verificação de iluminação de interiores, Rio de Janeiro, 1991

BRASIL. Ministério do Trabalho e Emprego. Portaria MTB № 3.214. NR -17 - Ergonomia (117.0007). 1978

GIUSEPPE, $\mathrm{Di}$ Bucchianico. Education in ergonomics between independence and interdisciplinary character of didactics at one of the Italian Faculties of Architecture. In: Anais do 17th World Congress on Ergonomics, Beijing, China, 2009

IAB- Instituto de Arquitetos do Brasil. Anotações sobre o PROJETO em Arquitetura. Contribuição para a sua regulação profissional. Rio de Janeiro. 2013

KOWALTOWSKI, Doris Catharine Cornelie Knatz; CELANI, Maria Gabriela Caffarena; MOREIRA,Daniel de Carvalho; PINA, Silvia Aparecida Mikami G.; RUSCHEI, Regina Coeli; SILVA, Vanessa Gomes da; LABAKI, Lucila Chebel; PETRECHE, João Roberto D.. Reflexão sobre metodologias de projeto arquitetônico. Ambiente Construído, v. 6, n. 2, p. 07-19, abr./jun. Porto Alegre. 2006.

PATTERSON, Cláudia Bartolo. Real space: the common dimension of Ergonomics and Architecture. In: Anais do 17th World Congress on Ergonomics-IEA 2009, Beijing, China. 2009

VILLAROUCO, Vilma. Tratando de ambientes ergonomicamente adequados: seriam ergoambientes? In.:Um novo olhar para o projeto: a ergonomia no ambiente construído. Organização Cláudia Mont'Alvão e Vilma Villarouco. - Teresópolis, RJ: 2AB. 2011

An ergonomic look at the work environment. In: Anais do 17th World Congress on Ergonomics, Beijing, China, 2009 